\title{
New construction: zero cycle aspects, modern methods and promising materials
}

\author{
Marina Panfilova ${ }^{1, *}$ \\ ${ }^{1}$ Moscow State University of Civil Engineering, Yaroslavskoye Shosse, 26, Moscow, 129337, Russia
}

\begin{abstract}
This work is aimed at studying the physicochemical processes and establishing the functional dependence of the strength parameters on the sulfur concentration in the composite. The introduction of sulfur in the composite contributes to a change in strength properties, an increase in frost resistance. The dependence of strength on sulfur concentration was studied. The experimental function is determined analytically by solving a system of linear algebraic equations consisting of canonical equations of a given approximating function. The behavior of the dependence of strength on the concentration of nanotubes at two intervals is plotted graphically. Further studies are needed to gain a complete picture of the composite and its characteristics. Nowadays, the results of determining the deformative characteristics are being processed, the impact of the water-cement ratio, the equivalent economic assessment are being studied. At present, an analytical description of the physicochemical and physicomechanical dependencies is being carried out, and an aggregate mathematical model is being built. The results will be presented to the public at subsequent scientific and research conferences.
\end{abstract}

\section{Introduction}

Modern regulation in construction dictates requirements and establishes provisions for the implementation of the entire life cycle of fixed assets.

Design decisions should ensure the preservation of the operational properties of both designed buildings and structures, and objects falling into the zone of influence of new construction. This aspect should be implemented for the construction, operation, and for other stages of the life cycle. In order to assess the impact of new construction, the relevant measures are being taken at the survey stage. So, it is necessary to make geotechnical assessment of the impact of new construction on the stress-strain state of the bases and foundations of the existing buildings, on the hydrogeological regime of the construction area, etc. The listed features are taken into account when justifying the choice of the type and construction of the foundation of a future building or structure. In the presence of cramped construction conditions, as well as geotechnical and other features of the construction site, most often there is a need to develop measures to strengthen the foundations of the future building or structure and the bases and foundations of buildings falling into the zone of influence of new construction.

\footnotetext{
* Corresponding author: $\underline{012340 @ \text { mail.ru }}$
} 
In modern practice, methods of cementation and installation of injection piles are common methods of strengthening the soil. Strengthening with injection piles makes it possible to transfer part of the loads from the building to more dense layers of soil. The disadvantages of this method of strengthening the foundations include low corrosion resistance, the difficulty of assessing the quality of the pile shaft, the unreliability of fixing the head of the pile in the case of a decrepit foundation, which subsequently acts as a grillage. Also, bored piles are among the methods of jet cementation of soils. Bored piles are the most widespread due to the economy and high bearing capacity. Piles can be concreted without casing: in an open well or with a well filled with clay mud; as well as with casing. The installation of bored piles in the casing with the extraction of soil can be carried out in any conditions, so this technology dominates in the leading foreign construction companies.

An important aspect of design solutions is the cost of their implementation. It is known that the cost of performing geotechnical work is from 10 to $40 \%$ of the total price of construction and installation works, depending on the complexity of geological conditions and the criticality level of the building.

There are following types of soil piles, depending on the material: concrete, reinforced concrete, jet grounding; clayey; combined.

For the installation of bored piles concreted in wells drilled in any soil below the groundwater level, it is necessary to provide for fixing the walls of the wells with clay mortar. The density of the clay mortar necessary for the production of work is determined from the calculation of maintaining the stability of the well walls. The mortar should have pronounced thixotropic properties that allow keeping the parameters of clay mortars unchanged for a long time. Mortars prepared on the basis of bentonite clays have the best indicators. To obtain high-quality clay suspensions, finely dispersed and highly plastic bentonite (montmorillonite) clays are most suitable.

The modern market of building materials is replenished with new composite materials. One of the strategic directions for the improvement of composites is the production of sulfur compositions using industrial wastes - sulfur, which is characterized by improved physical and mechanical properties, and also have abrasion resistance and acid resistance $[1]$.

The actual environmental, technical and economic problem in a number of regions of Russia and abroad is the recovery of sulfur, which is formed as a waste of oil and gas processing [2]. Thus, the development of technologies for sulfur composite materials is relevant in view of the fact that these materials have a number of valuable properties strength, resistance to abrasion, and water resistance $[3,4]$. Therefore, it is economically feasible to use sulfuric waste as components in the preparation of solutions used to strengthen soils.

The basis of the technology for producing high-quality and durable compositions is the modification of composite materials with molten sulfur. Vitrified or amorphized polymertype sulfur, penetrating into the pores, filling the voids, creates a protective layer, thereby several times increasing the waterproof properties, corrosion resistance to solutions of salts and weak acids. Cement minerals, interacting with sulfur in molten form (at a temperature of $120-150^{\circ} \mathrm{C}$ ), increase the strength properties of cement compositions, provide high quality material in terms of strength, water resistance, stability in an acidic environment [2].

However, the use of molten sulfur in composite solutions is impossible, since their preparation occurs without heating. Therefore, studies on the effect of sulfur additives on the properties of the composite solution are possible at ambient temperature, i.e. at a positive temperature [5]. 
This work is aimed at studying the physicochemical processes and establishing the functional dependence of the strength parameters on the sulfur concentration in the composite.

\section{Materials and Methods}

The main components of the composite solution are cement and bentonite. Cement grade 500 was used in the studies. Bentonite gives the system stability and regulates the plasticity and viscosity of the mixture. To improve the technological and sorption ion-exchange properties of bentonite, the company's enterprises modify it with soda ash and polymers [6$8]$.

To increase the rheological parameters of composite solutions, liquid glass is used. We used liquid glass with a density of $1.46 \mathrm{~g} / \mathrm{cm}^{3}$ and a silicate module of $2.7-3.4 \%$.

The chemical composition of $\mathrm{P}_{2} \mathrm{~T}_{2} \mathrm{~A}$ bentonite was obtained using a Spectroscan MAX spectrometer.

To test the frost resistance of the composition with the optimal sulfur concentration, samples were prepared: cubes $70 \times 70 \mathrm{~mm}$, stored for up to 28 days in a normal hardening chamber (6 samples). The frost resistance of the samples was determined by repeated freezing and thawing (in accordance with Russian State Standards GOST 10060-2012 and GOST 5802-86) of a $5 \% \mathrm{NaCl}$ solution at a temperature of minus $\left(25 \pm 50^{\circ} \mathrm{C}\right)$ using the accelerated method. A sample saturated with $\mathrm{NaCl}$ solution was placed in a dilatometer and kept for $30 \mathrm{~min}$, then placed in a freezer and frozen at a temperature drop to minus $(25 \pm$ $50^{\circ} \mathrm{C}$ ) at a rate of $0.3^{\circ} \mathrm{C} / \mathrm{min}$. The frost resistance tests of the composite solution with the optimum sulfur concentration were determined according to Russian State Standard GOST 10060.0-95.

\section{Results}

Bentonite is a highly dispersed layered aluminosilicate with the general formula $(\mathrm{Na}, \mathrm{K}$, Ca) $(\mathrm{Al}, \mathrm{Fe}, \mathrm{Mg})[(\mathrm{Si}, \mathrm{Al}) 4 \mathrm{O} 10]\left((\mathrm{OH}) 2 \cdot \mathrm{nH}_{2} \mathrm{O}\right)$. Bentonites mainly contain the $\mathrm{SiO}_{2}-\mathrm{Al}_{2} \mathrm{O}_{3}$ $-\mathrm{Fe}_{2} \mathrm{O}_{3}-\mathrm{CaO}$ system, which is the basis for hydraulic binders.

Figure 1 shows the oxide content in the composition of $\mathrm{P}_{2} \mathrm{~T}_{2} \mathrm{~A}$ bentonite obtained by the results of chemical analysis. Thus, bentonite has a chemical affinity for cement and other components of the composite.

In accordance with the obtained experimental data, the best results of the strength of the compositions on the 28th day of storage are achieved at a concentration of sulfur additives of $0.3 \%$ by weight of cement [9].

According to the results of the frost test, a frost resistance mark of a sulfur-containing sample F100 and a control sample without sulfur F50 was established. The results of the frost test prove that the addition of sulfur to the cement leads to more intensive hydration of the cement, an increase in the density of the cement stone.

The dependence of the strength of the composite solution on the sulfur concentration is quite complex, which is confirmed by the analysis of experimental data [9]. To build the experimental function, two-interval approximation by third degree polynomials was performed: the interval $\mathrm{x} \in[0 ; 0.35] ; \mathrm{x} \in[0.35 ; 1.8]$.

Based on the approximation results, approximating dependences were built for each concentration range (Fig. 2, 3). 


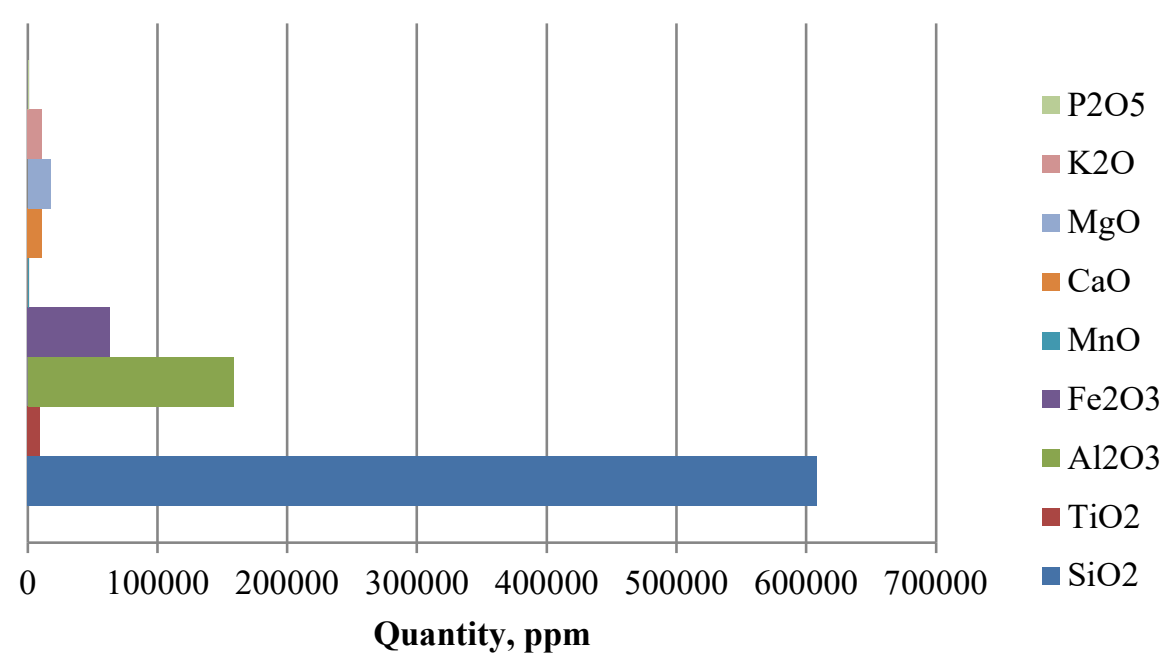

Fig. 1. The content of oxides in precast concrete.

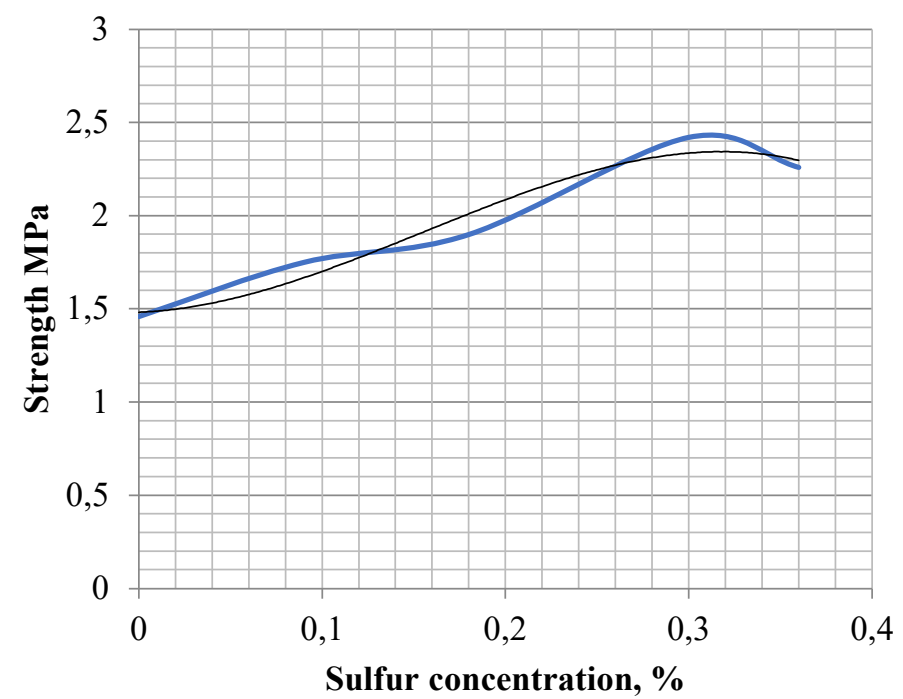

Fig. 2. Approximation of the dependence of strength on sulfur concentration for the interval $[0 ; 0.35]$

The reliability of the obtained approximation is confirmed by the value of the reliable approximation $\mathrm{R}^{2}$ that is equal to unity.

The resulting functions are the following expressions:

$$
\begin{aligned}
& F_{1}(x)=-49.958 x^{3}+23.264 x^{2}+0.3625 x+1.4819, \\
& F_{2}(x)=0.3001 x^{3}-0.6199 x^{2}-0.45 x+2.4883,
\end{aligned}
$$

where expression (1) is for the concentration interval $x \in[0 ; 0.35]$, (2) - for the concentration interval $x \in[0.35 ; 1.8]$.

Thus, the experimental function has the following form: 


$$
F(x)=\left\{\begin{array}{c}
0 \leq x \ll 0.3 ; F_{1}(x)=-49.958 x^{3}+23.264 x^{2}+0.3625 x+1.4819 \\
0.3 \leq x \leq 1.8 ; F_{2}(x)=0.001 x^{3}-0.6199 x^{2}+0.45 x+2.4883
\end{array}\right.
$$

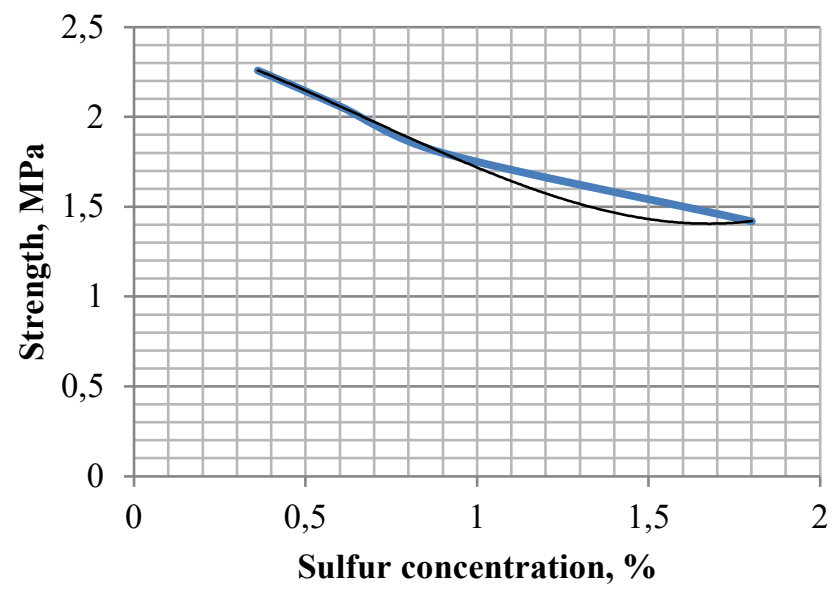

Fig. 3. Approximation of the dependence of strength on sulfur concentration for the interval $[0.35 ; 1.8]$

\section{Conclusions}

Bentonite and sulfur are chemically related to cement. The introduction of sulfur in the composite solution contributes to a change in strength properties, an increase in frost resistance. The dependence of strength on sulfur concentration was studied. The experimental function is determined analytically by solving a system of linear algebraic equations consisting of canonical equations of a given approximating function. The behavior of the dependence of strength on the concentration of nanotubes at two intervals is plotted graphically. Further studies are needed to gain a complete picture of the composite solution and its characteristics. Nowadays, the results of determining the deformative characteristics are being processed, the impact of the water-cement ratio, the equivalent economic assessment are being studied. At present, an analytical description of the physicochemical and physicomechanical dependencies is being carried out, and an aggregate mathematical model is being built. The results will be presented to the public at subsequent scientific and research conferences.

\section{References}

1. K.A. Nurbaturov, N.V. Bachilova, I.M. Dyo, V.S. Lysenko, T.A. Zaharova, Vestnik NAS RK 1(27), 115 (2008)

2. A.I. Vovk, Conc. 3, 89 (2012)

3. I.A. Solomin, PGS, 1, 20 (2014)

4. L.V. Kuharenko, N.V. Lichman, I.V.Nikitin, CM 8, 38 (2005)

5. Y. Kojima, A. Usuki, M. Kawasumi, et al, J.Polym.Sci. 31, 983 (1993)

6. N.P. Baranov, Vestnik MGSU 2, 139 (2009)

7. E.V. Korolev, Y.M. Bazhenov,V.A. Beregovoy, CM 9, 76 (2006)

8. M.I. Panfilova, N.I. Zubrev, M.V. Ustinova, et al,, Sci.R. 14, 172 (2015) 